\title{
Consciências Saudáveis e Almas Enfermas: Posturas Éticas Religiosas em William James
}

\author{
Rodrigo Barbosa Gomes Benevides
}

Universidade Federal de São Carlos)

\section{Resumo}

Trata-se aqui de examinar as noções de Sick Soul e Healthy-Mindedness de acordo com William James em sua obra Varieties of Religious Experience: A Study in Human Nature (1902). O pragmatismo de James se preocupa com o fenômeno religioso em termos de utilidade existencial de crenças que orientam ações no campo ético e, desse prisma, James percebe a religião como ferramenta fundamental para o equilíbrio psíquico humano, sendo o budismo e o cristianismo considerados os sistemas religiosos mais desenvolvidos da humanidade. Dito isso, o artigo apresenta os dois tipos básicos de postura ética aludidos, além de definir o que significa religião segundo James. Palavras-chave: William James. Ética. Psicologia. Religião.

\section{Healthy Minds and Sick Souls: Religious Ethical Stances in William James}

\section{Abstract}

The article examines the notions of Sick Soul and Healthy-Mindedness according to William James in his work Varieties of Religious Experience: A Study in Human Nature (1902). The pragmatism of James is concerned with religious phenomenon in terms of the existential usefulness of beliefs underlying ethical actions and, from this perspective, James perceives religion as a fundamental tool for human psychic balance, with buddhism and christianity being the most developed religious systems of humanity. That said, the paper shows these two basic ethical religious postures and presents James' view of religion.

Keywords: William James. Ethics. Psychology. Religion. 


\section{Mentes Sanas y Almas Enfermas: Posturas Eticas Religiosas en William James}

\section{Resumen}

Examinamos las nociones de Sick Soul y Healthy-Mindedness según William James en su obra Varieties of Religious Experience: A Study in Human Nature (1902). El pragmatismo de James tiene que ver con el fenómeno religioso en términos de la utilidad existencial de las creencias que subyacen a las acciones éticas y, desde esta perspectiva, James percibe la religión como una herramienta fundamental para el equilibrio psíquico humano, siendo el budismo y el cristianismo los sistemas religiosos más desarrollados de la humanidad. Dicho esto, mostramos estas dos posturas éticas religiosas básicas y presentamos el punto de vista de James sobre la religión.

Palabras clave:: William James. Ética. Psicología. Religión.

\section{Introdução}

Nas Gifford Lectures que compõem a obra Varieties of Religious Experience (1902), William James afirma que a religião deve ser compreendida primariamente como uma Weltanschaunng, isto é, uma cosmovisão. Desse modo, uma religião significa aquilo que abrange a soma de crenças que fundamentam ações no plano ético. O que de fato caracteriza uma postura religiosa, James argumenta, é "a maneira de nossa aceitação do universo." (JAMES, 2002, p. 37, tradução nossa). Em poucas palavras, "a religião de um homem pode então ser identificada com sua atitude, qualquer que seja, em direção ao que ele sente que seja a verdade primordial." (Ibid., p. 32). Essa verdade primordial diz respeito ao credo basilar que configura a condição existencial de um indivíduo em relação àquilo que ele considera ser o sentido da vida ou do cosmos e é precisamente essa a razão que James oferece para justificar sua linha investigativa na qual a análise de religiões institucionalizadas fica em segundo plano: "A verdade pura e simples é que para interpretar a religião deve-se, no fundo, examinar o conteúdo imediato da consciência religiosa."3 (Ibid., p. 15).

O foco de James, portanto, são as pessoas tomadas individualmente e o papel prático que determinada crença oferece para o surgimento e

\footnotetext{
1 "At bottom the whole concern of both morality and religion is with the manner of our acceptance of the universe."

2 "A man's religion might thus be identified with his attitude, whatever it might be, towards what he felt to be the primal truth."

3 "The plain truth is that to interpret religion one must in the end look at the immediate content of the religious consciousness."
} 
estabelecimento de certas posturas ou padrões comportamentais. Religião, no sentido particular de James, é a hierarquia de valores que estabelecem o norte existencial do homem; é a fórmula geral que orienta ações circunstanciais. Religião não é primordialmente sobre rituais, sacramentos ou tabus (apesar desses elementos serem indispensáveis na vida de uma pessoa inserida em algum credo institucionalizado), é sobre a fundamentação da ótica existencial que permeia ação e percepção de indivíduos. É sobre sentimentos e impulsos que, por estarem atrelados às individualidades, podem ser examinados via diários, cartas e obras de autobiografia.

Se a investigação é psicológica e não sobre religiões institucionalizadas, então são os sentimentos religiosos e impulsos religiosos que devem ser objeto de estudo, e devo me confinar àqueles fenômenos subjetivos mais desenvolvidos registrados na literatura, produzidos por homens articulados e plenamente conscientes, em obras religiosas e de autobiografia ${ }^{4}$. (JAMES, 2002, p. 8).

Sendo James um filósofo versado em psicologia, o intuito da obra é usar escritos pessoais religiosos de inúmeras pessoas e figuras históricas ${ }^{5}$ como uma janela para a natureza humana e, como bom pragmatista, indicar a utilidade concreta de tais sistemas de crenças. Desse modo, partimos aqui da noção de religião definida simplesmente como a internalização de uma cosmovisão (Weltanschaunng) que cobre os diversos domínios existenciais, ou melhor, "Religião, portanto, como peço agora que aceitem arbitrariamente, significará para nós os sentimentos, atos e experiências de homens individuais em sua solitude". (JAMES, 2002, p. 29).

James propõe duas categorias para descrever as disposições psicológicas básicas que lidam com esse aspecto ético geral da vida humana que concerne às religiões: Healthy-Mindedness (Consciência Saudável ou Equilíbrio Mental) e Sick Soul (Alma Enferma). Como afirma James, as categorias tratam de ilustrar

\footnotetext{
4 "If the inquiry be psychological, not religious institutions, but rather religious feelings and religious impulses must be its subject, and I must confine myself to those more developed subjective phenomena recorded in literature produced by articulate and fully self-conscious men, in works of piety and autobiography."

5 Na obra em questão, James se utiliza de escritos, diários e cartas com conteúdo religioso de pessoas anônimas e de personalidades como Ralph Waldo Emerson, Voltaire, Leon Tolstói, Baruch Spinoza, Marco Aurélio, Martinho Lutero, George Fox, Santo Francisco de Sales, Santo Agostinho, Santa Teresa, Walt Whitman, etc.

6 "Religion, therefore, as I now ask you arbitrarily to take it, shall mean for us the feelings, acts, and experiences of individual men in their solitude".
} 
"o contraste entre duas maneiras de enxergar a vida [...] duas concepções diferentes do universo de nossa experiência."7 (Ibid., p. 132). Pode-se muito bem oscilar entre as posições a depender do contexto, porém, em cada pessoa há sempre uma tendência predominante. Isso nos leva, como veremos, a diferentes perspectivas éticas que possibilitam a emergência de uma variedade de fenomenologias religiosas. Dito isso, o artigo se divide em dois momentos: primeiro, veremos como James define o fenômeno religioso; em seguida, examina-se as categorias de Consciência Saudável (Healthy-Mindedness) e Alma Enferma (Sick Soul).

I.

James não vê problema algum em admitir sua "falta de conhecimento aprofundado em teologia"8 (JAMES, 2002, p. 9), pois o propósito de Varieties of Religious Experience é vislumbrar aspectos da natureza humana que os fenômenos religiosos ajudam a trazer à tona. O pragmatismo de James está interessado na relevância que sistemas de crenças possuem no direcionamento da experiência fenomenológica individual. Examinar as cinco vias de Tomás de Aquino ${ }^{9}$ ou a relevância da patrística na crítica de heresias pagãs ${ }^{10}$ são questões que não estão no horizonte de James. Também não se trata de avaliar objetivamente circunstâncias e elementos factuais que estão na origem do corpo doutrinário de alguma religião. Essa atitude que visa apenas a realidade fática é o que James chama de existential judgement e não é por essa via que se pode compreender o aspecto das religiões que aqui interessa, a saber, a utilidade de crenças valorativas ou propositions of value, como diz James. Tomando o cristianismo para ilustrar essa diferença e demarcar seu objeto, James afirma o seguinte:

O que hoje é chamado de alta crítica da Bíblia é apenas o estudo da Bíblia desse ponto de vista fático, muito negligenciado pela igreja primitiva. Sob quais condições biográficas exatamente os escritores sagrados trouxeram suas várias contribuições à obra divina? E o que eles tinham exatamente em suas

\footnotetext{
7 " [...] we were brought into full view of the contrast between the two ways of looking at life which are characteristic respectively of what we called the healthyminded [...] and the sick souls [...] The result is two different conceptions of the universe of our experience."

8 "[...] lack of special theological learning".

9 Cf. AQUINO, Tomás de. Suma Teológica (2001).

10 Cf. AGOstinho. A Cidade de Deus. (1996); MORESCHINI, Claudio. História da Filosofia Patrística (2008); RUSSELL, Bertrand. História da Filosofia Ocidental Livro 2: A Filosofia Católica (2015).
} 
diversas mentes particulares quando proferiram suas declarações? Essas são claramente questões de facticidade histórica, e não se vê como a resposta a elas pode decidir de imediato a questão que persiste: de que maneira tal obra, com o detalhamento de seu surgimento tão definido, pode servir a nós como um guia para a vida e como revelação? ${ }^{11}$ (JAMES, 2002, pp. 9-10)

No limiar do estabelecimento de toda religião, antes mesmo da definição de rituais ou de textos canônicos, o que há são impulsos religiosos que, combinados, formam o que James chama de personal religion. A construção de uma visão de mundo divinizada e compartilhada por uma comunidade é um longo processo que, originariamente, parte de mentes singulares e atitudes individuais. É inegável a importância do estudo das minúcias dos sistemas religiosos em sua forma madura e o papel de organizações ou grupos em estados posteriores, mas o objeto aqui circunscrito visa os quadros mentais que estão na origem da construção de tais organizações. A esfera de investigação, portanto, é a de ordem psicológica. James se volta aos estados mentais presentes no prelúdio de organizações religiosas.

Agora, nessa aulas, proponho ignorar completamente o ramo institucional, não falar nada sobre a organização eclesiástica, considerar o mínimo possível a teologia sistemática e as ideias sobre os deuses propriamente ditos, e me confinar ao máximo à religião pessoal [personal religion] pura e simples. [...] os fundadores de toda igreja retiravam seu poder de sua comunhão direta e pessoal com o divino. Não apenas os fundadores sobre-humanos tais quais Cristo, Buda e Maomé, como todos os originadores de seitas cristãs foram assim; — então, a religião pessoal deve continuar a ser tomada como o objeto primordial, mesmo para aqueles que continuam a considerá-la incompleta ${ }^{12}$. (JAMES, 2002, pp. 28-29).

11 "What is nowadays called the higher criticism of the Bible is only a study of the Bible from this existential point of view, neglected too much by the earlier church. Under just what biographic conditions did the sacred writers bring forth their various contributions to the holy volume? And what had they exactly in their several individual minds, when they delivered their utterances? These are manifestly questions of historical fact, and one does not see how the answer to them can decide offhand the still further question: of what use should such a volume, with its manner of coming into existence so defined, be to us as a guide to life and a revelation?"

12 "Now in these lectures I propose to ignore the institutional branch entirely, to say nothing of the ecclesiastical organization, to consider as little as possible the systematic theology and the ideas about the gods themselves, and to confine myself as far as I can to personal religion pure and simple. [...] the founders of every church owed their power originally to the fact of their direct personal communion with the divine. Not only the superhuman founders, the Christ, the Buddha, Mahomet, but all the originators of Christian sects have been in this case; - so personal religion should still seem the primordial thing, even to those who continue to esteem it incomplete." 
As manifestações primordiais de diferentes cosmovisões são o objeto, mas como se deve estudá-las? Crenças religiosas expressam valores sobre o sentido último da realidade e valores não podem ser examinados por uma análise fisiologicamente reducionista. James ironiza esse tipo de compreensão ao enumerar teses infrutíferas que tentam relacionar o desenvolvimento da melancolia sobre o universo (fonte para divagações religiosas) com "má digestão" ou problemas no "fígado"; alegria em estar em uma igreja como um sintoma de "constituição histérica"; ou ansiedade como resultado da falta de "exercício ao ar livre" 13 (JAMES, 2002, p. 14). Porém, de todas as explicações de cunho reducionista, James reserva maior atenção para a hipótese que atrela religião à sexualidade. Apresentada como "exemplo plenamente desenvolvido do mesmo tipo de raciocínio", James se opõe veementemente às análises que tendem a "criticar as emoções religiosas ao mostrar uma conexão entre elas e a vida sexual." 14 (Idem). Valendo-se de uma estratégia de reductio ad absurdum, James não nega o substrato físico de nossas operações mentais, tampouco o aspecto fisioquímico envolvido no irrompimento e no controle de patologias como depressão ou ansiedade, entretanto, ele indica que a tentativa de conectar o surgimento de questões da esfera religiosa com o funcionamento de nossa sexualidade é tão arbitrário quanto "interpretar a religião como uma perversão do sistema respiratório." 15 (JAMES, 2002, p. 15) ou "chamar a religião de uma aberração do sistema digestivo"16 (Ibid., 14). James, portanto, é partidário da perspectiva que rejeita teses excessivamente reducionistas. Associar impulsos religiosos a disfunções fisiológicas significa não compreender as minúcias da ordem psíquica que perpassa as questões de matriz existencial. Reduzir as proposições religiosas a determinadas funções orgânicas seria como associar um movimento estético a um modo de produção econômico específico. Por mais que tais domínios sejam inseparáveis, existe um grau de desacoplamento que permite uma liberdade de variação nas esferas religiosa e estética, pois nem todo fenômeno

\footnotetext{
13 "William's melancholy about the universe is due to bad digestion — probably his liver is torpid. Eliza's delight in her church is a symptom of her hysterical constitution. Peter would be less troubled about his soul if he would take more exercise in the open air, etc."

14 "A more fully developed example of the same kind of reasoning is the fashion, quite common nowadays among certain writers, of criticising the religious emotions by showing a connection between them and the sexual life."

15 "In fact, one might almost as well interpret religion as a perversion of the respiratory function."

16 "But then why not equally call religion an aberration of the digestive function".
} 
existencial está plenamente condicionado pelo substrato objetivo. É fato que artistas e pessoas religiosas definitivamente refletem aspectos da organização econômica ao seu redor ou de seu estado fisiológico, mas essa causalidade não é determinante, nem única.

Parece-me que poucas concepções são menos instrutivas do que essa re-interpretação da religião como sexualidade pervertida. [...] Mas se os defensores da teoria sexual dizem que, sem as contribuições químicas que os órgãos sexuais fazem ao sangue, o cérebro não estaria nutrido para efetuar atividades religiosas, essa última proposição pode ou não ser verdade, mas, de qualquer forma, torna-se profundamente inútil: não podemos deduzir nenhuma consequência dela que nos ajude a interpretar o sentido e o valor da religião. Nesse sentido, a vida religiosa depende tanto do baço, do pâncreas e dos rins quanto do aparato sexual, e assim toda a teoria perde seu sentido ao evaporar em uma vaga afirmação generalista sobre alguma forma de dependência da mente sobre o $\operatorname{corpo}^{17}$. (JAMES, 2002, pp. 14-15)

Reduzir fenômenos religiosos às funções sexuais é um exemplo daquilo que James chama de medical materialism. Desse ponto de vista, qualquer evento mental ou sistema de crenças se torna passível de descrição em termos médicos ou fisiológicos, descartando assim a possibilidade da análise psicológica sobre valores éticos que, em última instância, ultrapassariam a mera decomposição materialista de um fato. James ilustra esse tipo de materialismo vulgar ao sugerir a seguinte hipótese para a célebre conversão do apóstolo Paulo de Tarso: "O materialismo médico [medical materialism] descarta São Paulo ao classificar sua visão a caminho de Damasco como a decorrência de uma lesão no córtex occipital de alguém epiléptico." ${ }^{18}$ (JAMES, 2002, p. 16). Porém, e é aqui que entra o

17 "It seems to me that few conceptions are less instructive than this re-interpretation of religion as perverted sexuality. [...] If now the defenders of the sex-theory say that this makes no difference to their thesis; that without the chemical contributions which the sex-organs make to the blood, the brain would not be nourished so as to carry on religious activities, this final proposition may be true or not true; but at any rate it has become profoundly uninstructive: we can deduce no consequences from it which help us to interpret religion's meaning or value. In this sense the religious life depends just as much upon the spleen, the pancreas, and the kidneys as on the sexual apparatus, and the whole theory has lost its point in evaporating into a vague general assertion of the dependence, somehow, of the mind upon the body."

18 "Medical materialism finishes up Saint Paul by calling his vision on the road to Damascus a discharging lesion of the occipital cortex, he being an epileptic." 


\section{Rodrigo Barbosa Gomes Benevides}

pragmatismo de James, mesmo que a origem da visão de São Paulo estivesse de fato ligada a um distúrbio do córtex occipital, isso obrigatoriamente implicaria na rejeição de sua significação e utilidade ética-existencial ${ }^{19}$

Para muitos, explicações de ordem naturalista onde se indica a origem de um determinado estado mental de caráter espiritual servem para rejeitar peremptoriamente o valor de crenças religiosas. No entanto, aqui a filosofia pragmatista é mais uma vez retumbante: "como uma explicação factual de eventos de um histórico mental pode decidir, de uma maneira ou de outra, sobre sua relevância espiritual?"20 (JAMES, 2002, p. 16). Se tudo é redutível aos mecanismos orgânicos de nossa corporeidade, então, necessariamente, o mesmo deve valer para posições do espectro que vai do ceticismo ao ateísmo. Desse modo, negar o valor dos impulsos religiosos devido a sua "causação orgânica" é simplesmente "ilógico e arbitrário"21. (Ibid., p. 17). James refuta o materialismo médico reducionista ao extrapolar suas premissas, levando-o a conclusões absurdas ou, no mínimo, impossíveis de refutação, dado seu teor excessivamente generalista que, no final das contas, em nada acrescenta. Se, supostamente, boa parte do Novo Testamento provém de um homem com desequilíbrio no córtex, com certeza podemos igualmente encontrar a raiz fisiológica do atéismo de alguém como Sartre, Freud ou Žiž̌ek. Porém, James diria, qual a relevância dessas explicações na refutação do teísmo cristão ou do ateísmo contemporâneo?

De acordo com o postulado de psicologia referido a pouco [medical materialism], não há um único estado mental, superior ou inferior, saudável ou mórbido, que não possua um processo orgânico como sua condição. Teorias científicas são organicamente condicionadas tanto quanto emoções religiosas; e se apenas conhecêssemos os fatos com a devida profundidade, veríamos com clareza "o fígado" determinando a posição do resoluto ateu de maneira tão decisiva quanto a convicta ansiedade do Metodista sobre sua alma. Quando o fígado altera de uma dada maneira o sangue que o circula, obtém-se um metodista, quando alterado de outra maneira, obtém-se a mentalidade ateia. [...] Tudo

19 Para uma devida análise fenomenológica do cristianismo primitivo a partir do exame das epístolas paulinas, Cf. HEIDEGGER, Martin. Fenomenologia da Vida Religiosa (2014).

20 "[...] how can such an existential account of facts of mental history decide in one way or another upon their spiritual significance?".

21 "To plead the organic causation of a religious state of mind, then, in refutation of its claim to possess superior spiritual value, is quite illogical and arbitrary". 
é igualmente fundado organicamente, seja de conteúdo religioso ou nãoreligioso $^{22}$. (JAMES, 2002, pp. 16-17)

Em outras palavras, não se nega o fundamento material de nossos estados mentais (o que seria ilógico para alguém com formação em medicina como James). A questão é que os reducionistas proponentes do materialismo médico visam refutar o valor dos estados mentais religiosos ao tentar traçar suas origens orgânicas, como se houvesse alguma conexão entre origem e utilidade. No entanto, diz James, se realmente esse é o critério para descartarmos crenças e proposições de estados mentais superiores, então deve-se negar igualmente as proposições científicas, políticas, agnósticas e ateias, pois todas possuem no organismo biológico seu ponto de origem. Se o materialismo médico realmente seguisse a rigor sua tese, então "nenhum de nossos pensamentos ou sentimentos, nem nossas doutrinas científicas, nem mesmo nossas descrenças [dis-beliefs], poderiam reter algum valor como revelações da verdade, pois tudo, sem exceção, flui do estado corporal momentâneo de seu possuidor." 23 (JAMES, 2002, p. 17). O aspecto enviesado desse tipo de materialismo fica claro na arbitrariedade de tal rejeição pueril e, para James, a única conclusão possível é que "Os materialistas médicos, portanto, não passam de dogmáticos defasados." ${ }^{24}$ (Ibid., p. 20).

Ao indicar a inocuidade em preterir estados religiosos em razão de sua raiz orgânica, James demonstra seu pragmatismo quando defende que, mesmo se partirmos do ponto de vista unicamente evolucionista, a religião continua a ser um fenômeno essencial na regulação psíquica. Isso obviamente não significa que qualquer coisa que traga alguma utilidade seja

22 "According to the general postulate of psychology just referred to [medical materialism], there is not a single one of our states of mind, high or low, healthy or morbid, that has not some organic process as its condition. Scientific theories are organically conditioned just as much as religious emotions are; and if we only knew the facts intimately enough, we should doubtless see "the liver" determining the dicta of the sturdy atheist as decisively as it does those of the Methodist under conviction anxious about his soul. When it alters in one way the blood that percolates it, we get the methodist, when in another way, we get the atheist form of mind. [...] They are equally organically founded, be they of religious or of non-religious content."

23 " $[\ldots]$ none of our thoughts and feelings, not even our scientific doctrines, not even our dis-beliefs, could retain any value as revelations of the truth, for every one of them without exception flows from the state of their possessor's body at the time."

24 "The medical materialists are therefore only so many belated dogmatists". 
verdadeira. Não é esse o cerne do pragmatismo ${ }^{25}$. Para James, é indiscutível que "Aquilo que imediatamente provoca uma sensação 'boa' nem sempre é o mais "verdadeiro"”26 (JAMES, 2002, p. 18). O escopo da investigação, como dito, gira em torno do campo comportamental, ou seja, trata-se aqui de compreender como crenças religiosas se desdobram em ações e como elas ajudam na saúde psicológica do indivíduo. A utilidade das religiões, portanto, é algo indiscutível. Todavia, ainda resta saber se, mesmo sendo algo inegavelmente consentâneo, a religião possui algum grau de abertura ao real no sentido gnosiológico. Com isso, vejamos brevemente o que o pragmatismo tem a dizer sobre a relação entre verdade e utilidade.

Hilary Putnam (2010), um dos maiores continuadores da tradição pragmatista, é enfático ao defender James das corriqueiras distorções que diversos filósofos fazem da teoria pragmatista da verdade. De antemão, devese ressaltar que Peirce, James ou Dewey nunca defenderam um relativismo que impossibilitaria a noção de que algo possa ser definido como verdadeiro. O que a filosofia pragmatista tenta apontar é o caráter transitório de determinadas descrições de objetos (seja nas ciências naturais ou sociais) que permitem a caracterização da verdade como um conjunto de desdobramentos práticos compartilhados por uma comunidade que é usado até que se prove o contrário. Putnam lembra que é comum encontrar críticas equivocadas que "terminam dizendo que James propôs a teoria de que 'a verdade' significa 'ter boas consequências" (PUTNAM, 2010, p. 212). No entanto, como dito, na medida em que novas informações são incorporadas em um determinado campo do saber (ética, química, economia, etc.), aquilo que era últil anteriormente passa a ser descrito de outro modo, possibilitando até mesmo a mudança de sua prática. De qualquer modo, há ainda uma crítica ainda mais errônea em relação ao pragmatismo de James e a verdade, a saber, a acusação de que o filósofo americano defenderia uma perspectiva individualista da verdade, o que evidentemente é falso.

Alguns críticos até mesmo leem James afirmando - mesmo contrário aos repetidos enunciados, explícitos e implícitos, em seus textos - de que se as consequências de se acreditar em p são boas para você, então p é "verdadeiro

25 Cf. JAMES, William. Pragmatism and Other Writings (2000); BRANDOM, Robert B. Perspectives on Pragmatism: Classical, Recent and Contemporary (2011); PUTNAM \& PUTNAM, Pragmatism as a Way of Life: The Lasting Legacy of William James and John Dewey (2017).

26 "What immediately feels most 'good' is not always most 'true". 
para você". Deixe me dizer de uma vez por todas que James nunca usou as noções "verdadeiro para você" ou "verdadeiro para mim". A verdade, ele insistia, é uma noção que pressupõe uma comunidade, e, como Peirce, ele sustentava que fosse uma comunidade o mais ampla possível, uma comunidade de todas as pessoas (e possivelmente de todos os seres conscientes) no longo prazo, é a única relevante. (PUTNAM, 2010, p. 212)

Com a defesa do aspecto intersubjetivo na definição daquilo que é verdadeiro, pode-se descartar de vez o despautério pueril lançado contra o pragmatismo, pois a ideia de que "um enunciado é verdadeiro se tornar as pessoas que acreditam nele felizes subjetivamente - é explicitamente negado por ele [James]." (PUTNAM, 2010, p. 213). Além disso, a determinação final acerca de algo é contemplada por James. Decerto há questões que o homem provavelmente nunca poderá chegar a conclusões definitivas, mas na obra de James não existe a defesa de que toda e qualquer investigação é impossível de apresentar soluções categóricas. Portanto, a verdade não é algo descartado ou distorcido no pragmatismo americano.

James acreditava que a verdade deve ser de tal maneira que seja possível dizer como compreendê-la. E como Peirce, ele frequentemente identifica a verdade com a "opinião final”, ou seja, não com o que é confirmado hoje, mas com aquilo que está determinado a ser confirmado. Se a investigação continuar por tempo suficiente, e de modo responsável e falibilista. A verdade é "o destino do pensamento", escreveu James. (PUTNAM, 2010, p. 214).

Onde entra, então, a questão da relação entre praticidade e verdade salientada pelos pragmatistas? Ela se dá a partir da conexão entre compreensão e confirmação. A confirmação se dá no plano prático de nossas vidas, enquanto que a compreensão reside no plano teorético gnosiológico. É evidente que ambas as esferas estão conectadas, porém, uma ação que se revela útil pode continuar a ser útil mesmo que a teoria por trás dela esteja incompleta. Por exemplo, a humanidade conseguiu chegar à lua devido aos avanços da física newtoniana, entretanto, a física do séc. XX demonstrou a incompletude da mecânica clássica. A visão quântica da natureza, porém, não significou o completo descarte do pensamento de Newton, pois, mesmo que hajam falhas em seu modelo, seu desdobramento prático continua relevante e útil. Do ponto de vista teorético, portanto, resta incorporar aquilo de verdadeiro e válido em Newton dentro de um sistema que englobe as novas 
descobertas da física com os postulados do paradigma anterior. Em suma, não se pode confundir a verdade última sobre determinado tópico com as possibilidades de manipulações e ações que o envolvem.

Entender o que é a verdade em um determinado caso e entender o que é a confirmação são habilidades inter-relacionadas, e isso é algo que os pragmatistas estão entre os primeiros a ressaltar, mesmo que (como todo filósofo que é pioneiro na formulação de um insight) eles tenham formulado suas ideias com simplicidade. A "teoria da Verdade" de James pode ser que esteja errada, mas ele sabia perfeitamente bem a diferença entre a verdade e a confirmação, e ele não meramente confundiu as duas. Ele acreditava que, já que nossas afirmações adquirem sua substância a partir dos diferentes papéis que desempenham em nossas vidas, uma definição da verdade irá adquirir sua substância a partir de uma definição concomitante de como alcançá-la. (PUTNAM, 2010, pp. 214-215).

O pragmatismo, portanto, sempre está a pensar a verdade em termos de práticas humanas, o que leva Putnam a associá-lo à filosofia de Wittgenstein. No fundo, qualquer discussão sobre a definição acerca de algo está conectada com o que se pode fazer, ou seja, "Assim como James tenta 'humanizar' a noção de verdade, vê-la como instrumento humano (como ele vê todos os conceitos), e não como uma ideia que caiu do céu, Wittgenstein insiste que todas as nossas noções dependem de nossa 'forma de vida'." (PUTNAM, 2010 , p. 219). Toda verdade que é aceita em uma comunidade humana não é apenas algo etéreo que foi contemplado e traduzido em termos proposicionais. A verdade é algo que está conectado com o que se faz dela. Aquilo tomado como verdadeiro é sempre algo que se insere em práticas que pertencem a um determinado contexto cultural de um grupo (seja a sociedade como um todo ou parcelas específicas dela). Além disso, não podemos esquecer a clara diferença que há entre verdades e ações práticas no âmbito científico/tecnológico e no âmbito ético/existencial. As da segunda esfera, como se sabe, permitem uma maior elasticidade em termos de quais crenças são admitidas, daí James propor em The Will to Believe (1896) a diferenciação entre "questões puramente teóricas, que dizem respeito à ciência, e as questões práticas, das quais podemos tirar proveito, mesmo que não sejam conhecimentos considerados seguros do ponto de vista científico. Entre estas últimas, incluem-se as crenças religiosas." (MATTOS, 2010, p. 112). Com isso em mente, deve ficar claro que o critério de verdade na 
esfera ética, para James, assume um caráter de aceitabilidade menos rígido, isto é, as consequências práticas possuem um peso maior para definir se uma determinada crença possui coerência ou não, algo que ecoa o argumento posterior de Richard Rorty sobre a hereditariedade kantiana do pragmatismo.

Para Rorty, o pragmatismo não começa com Peirce, mas com Kant, quando este afirma que a verdade empírica é uma questão de coerência entre nossas representações, e não uma correspondência dessas representações com o modo como as coisas são em si mesmas. Não conhecemos a coisa-em-si, mas apenas o fenômeno. [...] As crenças religiosas devem ser testadas com base nas consequências da conduta do sujeito enquanto ele vive sua existência. [...] A verdade é uma característica das crenças, as quais nos ajudam a lidar com nossas experiências cotidianas. As crenças que melhor se adaptam a isso podem ser chamadas de verdadeiras. Nesse sentido, James defende o exercício da fé como uma possibilidade plausível. Embora não possamos demonstrar a existência de Deus, James defenderá o direito de crer. (MATTOS, 2010, pp. 120-122).

Desse modo, reitera-se: a análise pragmatista das proposições religiosas acentua o exame de suas consequências comportamentais e não dos pormenores teológicos e ontológicos associados aos sistemas institucionalizados mais desenvolvidos. Como diz David Scott (2000), a filosofia do pragmatismo, então, não só é favorável à adoção de crenças religiosas devido a serventia existencial, como ela também promove a aceitação de credos diversos: 'Para James, 'pragmatismo' como filosofia influencia nossa atitude em relação à religião. Isso em termos tanto do que constitui 'religião' como na consideração do pluralismo religioso." ${ }^{27}$ (SCOTT, 2000 , p. 333, tradução nossa). Tal postura, portanto, indica a sugestão de James acerca da validade prática de diferentes religiões para diferentes propósitos e indivíduos. Cada pessoa pode encontrar conforto ou sabedoria espiritual em textos ou práticas de religiões que não necessariamente são suas. Um judeu não precisa abdicar de sua religião para incorporar elementos prático-existenciais do budismo ou do cristianismo em sua vida. Vale ressaltar que James não defende um pluralismo no qual todas as proposições de todas as religiões são verdadeiras e, desse modo, ontologicamente compatíveis, o que seria impossível. Sua preocupação, novamente, se dá no terreno ético da

27 “For James, 'pragmatism' as a philosophy shapes one's attitude towards religion. This was both in terms of what actually constitutes 'religion' and in considering religious pluralism." 
existência. As questões teológicas, ao que tudo indica, estão fora do alcance da determinação comunal/inter-subjetiva da verdade, mas, em termos de utilidade comportamental, é inegável a possibilidade de um pluralismo religioso que James não apenas defendia como filósofo como praticava como indivíduo (seu contexto familiar cristão não o impossibilitou de incorporar vários aspectos valiosos de diferentes crenças religiosas e filosóficas). De qualquer modo, a visão pragmatista sobre a verdade possui um caráter deveras abrangente. Ela não resulta de nenhum relativismo, como demonstramos, tampouco de pontos de vista individualistas. No que diz respeito às questões éticas, o pragmatismo compreende que crenças religiosas demonstram um valor de utilidade inquestionável. Se adotarmos o ponto de vista evolucionista e tentarmos compreender o fenômeno religioso apenas como um mecanismo de manutenção da vitalidade de indivíduos e comunidades, ainda assim deve-se admitir um grau de verdade na religião, pois ela funciona como o substrato do sentido que faz o mundo ser desvelado de tal modo que a conexão existencial do homem com a realidade vivida é enriquecida. Se o deus X ou Y é o verdadeiro, ou se deus algum existe, são questões pertinentes e, talvez um dia, passíveis de respostas definitivas, no entanto, até lá a verdade prática das religiões se confirma a cada dia e o pragmatismo não vê problema em admitir sua coerência nesse âmbito específico.

No final das contas, nós somos absolutamente dependentes do universo; e de sacrifícios e entregas de diversos tipos [...] A religião, pois, torna fácil e prazeroso aquilo que, de qualquer maneira, é necessário; e se essa é a única ação que consegue atingir esse resultado, sua importância vital como faculdade humana é justificada acima de qualquer disputa. Ela se torna um órgão essencial de nossa vida, desempenhando uma função que nenhuma outra parte da nossa natureza pode cumprir com a mesma eficiência. Do ponto de vista meramente biológico, por assim dizer, essa é uma conclusão à qual, até onde posso ver, seremos inevitavelmente levados ${ }^{28}$. (JAMES, 2002, p. 45).

28 "For when all is said and done, we are in the end absolutely dependent on the universe; and into sacrifices and surrenders of some sort [...] Religion thus makes easy and felicitous what in any case is necessary; and if it be the only agency that can accomplish this result, its vital importance as a human faculty stands vindicated beyond dispute. It becomes an essential organ of our life, performing a function which no other portion of our nature can so successfully fulfill. From the merely biological point of view, so to call it, this is a conclusion to which, so far as I can now see, we shall inevitably be led". 
De uma perspectiva estritamente darwinista, portanto, crenças religiosas formam cosmovisões que nos levam a adotar posturas providenciais à manutenção de nossa vitalidade existencial. Porém, do mesmo modo que o pragmatismo não aceita que tudo que é bom seja necessariamente verdadeiro, lembremos que nem tudo que é necessário é forçosamente prazeroso. Muitas vezes os sistemas religiosos estipulam ações e códigos morais de conduta que, pelo contrário, dificultam a vida cotidiana de um indivíduo pela sua rigidez ou nível de ascese. Religião não é sinônimo de felicidade ou bemestar imediato. Um credo não é redutível a fórmulas de regozijo. É ponto pacífico que, e.g., tabus do judaísmo ou práticas budistas de meditação não são proposições que visam um simples deleite de seus praticantes do tipo que se vê em manuais vulgares de auto-ajuda. Toda crença sistematicamente desenvolvida envolve sacrifícios morais, físicos e existenciais que, não raramente, vão na contramão do puro hedonismo ou da busca irrefletida de felicidade: "em suas manifestações mais características, a felicidade religiosa não é um mero sentimento de fuga. A felicidade religiosa já não visa fugir."29 (Ibid., p. 43). Em outras palavras, somente algo como a adoção genuína de impulsos religiosos ou de posturas éticas quaisquer explicam o porquê dos homens adotarem práticas ascéticas ${ }^{30}$. É parte integrante de diferentes credos o poder de ressignificar a dor e os sacrifícios da existência.

Existem santos que literalmente se alimentaram do princípio negativo, da humilhação e da privação, e de pensamentos sobre sofrimento e morte, - suas almas crescem em felicidade na exata proporção do deterioramento cada vez mais intolerável de seu estado exterior. Nenhuma emoção além da religiosa pode levar um homem a essa situação peculiar ${ }^{31}$. (JAMES, 2002, p. 44)

29 "But in its most characteristic embodiments, religious happiness is no mere feeling of escape. It cares no longer to escape."

30 Práticas como a do estoicismo podem revelar atitudes ascéticas que se distanciam da concepção usual de religião, porém, como deixamos claro no decorrer do texto, aqui está assumida a posição de James na qual religião significa simplesmente a cosmovisão totalizante que norteia cada situação existencial de um indivíduo. Portanto, mesmo que a ascese seja um fenômeno separável de sistemas religiosos institucionais, ela deve ser considerada como tradução comportamental de uma postura ética religiosa, no sentido pragmatista de James.

31 "There are saints who have literally fed on the negative principle, on humiliation and privation, and the thought of suffering and death, — their souls growing in happiness just in proportion as their outward state grew more intolerable. No other emotion than religious emotion can bring a man to this peculiar pass." 
Como se vê, para além das questões metafísicas pertencentes à teologia, James lida com a religião no sentido de uma cosmovisão que enseja determinados comportamentos e estados psicológicos individuais. Desse prisma psicológico-pragmático, a avaliação de James do fato religioso é univocamente positiva: "A religião é possível e bem recebida pelo pragmatismo americano." (MATTOS, 2010, p. 115). A base religiosa se mostra essencial ao demonstrar, de modo inegável, utilidade prática no terreno ético, independente da origem das crenças em questão. Seja por revelação divina, intelecção analítica ou oscilação patológica no córtex pré-frontal, o que importa aqui é a diferença no terreno prático: "Em outras palavras, não a sua origem, mas o modo que funciona no geral [...] No final das contas, deve-se voltar ao nosso critério empirista: Pelos frutos os conhecereis, não pelas suas raízes." 32 (JAMES, 2002, p. 21).

Se devemos, diz James, "julgar a vida religiosa apenas pelos seus resultados"33 (Ibid., p. 22), então apenas três são "os únicos critérios disponíveis" 34 (Ibid., p. 19) para um exame adequado de crenças, a saber, esclarecimento imediato [immediate luminousness]; razoabilidade filosófica [philosophical reasonableness]; e utilidade moral [moral helpfulness]. Desse modo, independentemente do estado neurológico de pessoas como Paulo de Tarso, Sidarta Gautama ou qualquer um que exerça papel na instauração de um credo sistematizado, todo juízo acerca de visões religiosas deve partir de tais critérios. Daí James argumentar que "Nas ciências naturais e na tecnologia ninguém pensa em refutar opiniões demonstrando a constituição neurótica do autor." ${ }^{35}$ (Ibid., p. 19), já que o cerne da questão são os desdobramentos de um dado conjunto de proposições e não como se chegou a elas. Dito isso, mais uma vez pergunta-se: qual é, afinal, o âmago da religião? Pode-se tentar defini-la como uma mera projeção do homem ${ }^{36}$ ou como resposta ao medo pré-científico do mundo natural ${ }^{37}$. Há também, como dito acima,

\footnotetext{
32 "In other words, not its origin, but the way in which it works on the whole [...] In the end it had to come to our empiricist criterion: By their fruits ye shall know them, not by their roots."

33 "At any rate you must all be ready now to judge the religious life by its results exclusively".

34 "Immediate luminousness, in short, philosophical reasonableness, and moral helpfulness are the only available criteria."

35 "In the natural sciences and industrial arts it never occurs to any one to try to refute opinions by showing up their author's neurotic constitution."

36 Cf. FEUERBACH, Ludwig. Preleções Sobre a Essência da Religião (2009).

37 Cf. HUME, David. História Natural da Religião (2004).
} 
a tentativa de ver na sexualidade ${ }^{38}$ e em sentimentos de dependência ${ }^{39}$ sua origem. Para James, entretanto, trata-se de algo diretamente ligado ao poder de interpretação existencial do cosmos e a sua decorrente influência no comportamento individual. Nessa ótica, até mesmo os deuses como entidades são dispensáveis. Lembremos do caso do budismo: "Há sistemas de pensamento que todos chamam de religiosos e, no entanto, não assumem positivamente um Deus. O Budismo se enquadra nesse caso." ${ }^{40}$ (Ibid., p. 30). Mesmo sem um Deus nos moldes do monoteísmo abraâmico ou do panteão politeísta de gregos ou hindus, é lugar comum aceitar que há uma cosmovisão budista, isto é, uma Weltanschanung originada na figura de Sidarta Gautama que orienta a existência individual e a preenche com a sensação contínua de que há um aspecto divino que perpassa a constituição do universo e das vidas humanas. Outro exemplo é o xintoísmo japonês que, assim como o sistema budista, indica que "devemos interpretar o termo 'divino' de maneira abrangente, referindo-se a qualquer objeto celestial, seja uma divindade concreta ou não." ${ }^{11}$ (Ibid., p. 32). Segundo James, portanto, não há a obrigatoriedade de deuses para que um sistema seja tido como religioso. Um credo ético-existencial não pode ser reduzido a uma pura adoração de seres específicos, mesmo que isso seja um componente compartilhado por inúmeras religiões institucionalizadas. Há algo que transcende a ideia de deuses e que está ligado às questões de ordem prática, levando James à conclusão de que também "Devemos, portanto, do ponto de vista experiencial, chamar de 'religiões' esses credos sem deuses ou quase sem deuses." ${ }^{42}$ (Idem).

Para caracterizar uma postura religiosa, é útil pensá-la como a lente pela qual o universo é percebido, é o tipo de conduta existencial que permeia a vida diária, fundamentando assim a 'visão religiosa' de um indivíduo. É a cosmovisão que norteia as ações efetivadas em circunstâncias particulares. Podemos nos sentir alheios ou íntimos com a realidade, gratos ou ressentidos, diminuídos ou engrandecidos. Podemos sentir que fazemos parte de um grande plano ou que tudo não passa de um encadeamento contingente

\footnotetext{
38 Cf. FREUD, Sigmund. Totem e Tabu (2012).

39 Cf. FREUD, Sigmund. O Futuro de uma Ilusão (2010).

40 "There are systems of thought which the world usually calls religious, and yet which do not positively assume a God. Buddhism is in this case."

41 "[...] we must interpret the term "divine" very broadly, as denoting any object that is godlike, whether it be a concrete deity or not."

42 "We must therefore, from the experiential point of view, call these godless or quasi godless creeds 'religions"'.
} 
onde nada nem ninguém possui um sentido último. Podemos perceber a humanidade como irmãos que compartilham a mesma jornada ou como seres atomizados perpetuamente em disputa, etc. Essa reação básica à totalidade da existência define a nossa postura ética em relação a tudo que nos ocorre. É essa conduta geral que deve ser compreendida como "a mais completa de nossas respostas à questão 'Qual é o caráter desse universo em que vivemos?"'43 (Ibid., p. 33). Quando um budista aceita as Quatro Nobres Verdades, sua atitude para com a existência parte do fato de que, primeiro, há um sofrimento inerente à vida; segundo, esse sofrimento parte do desejo; terceiro, esse desejo deve ser mitigado; por fim, essa mitigação ocorre pela adoção do Nobre Caminho Óctuplo. Independente da existência de um ser divino superior e criador do universo, temos aqui uma interpretação geral, uma Weltanschauung que fundamenta nosso modo de reagir às situações particulares e se portar perante ao mundo. Com isso, James se pergunta: "Por que não chamar de religião essas nossas reações, independente do caráter específico que eles possam ter?" 44 (Idem). São tais reações que influem nas atitudes singulares que serão tomadas e, se alguma coisa deve ser definida como comportamento religioso, é exatamente a interiorização de normas éticas generalistas que conduzem atitudes circunstanciais. Apoiado nisso, o indivíduo "acrescenta à vida um encantamento que não é racional ou logicamente dedutivel de qualquer outra coisa. [...] O sentimento religioso, portanto, é uma adição absoluta no alcance da vida de uma pessoa. Ele lhe dá uma nova esfera de poder." 45 (Ibid., p. 42, grifo nosso). O sentimento religioso, pois, é composto por axiomas existenciais que resistem à decomposição reducionista do materialismo vulgar por se encontrarem na esfera de valores que, por sua vez, obedecem aos critérios pragmatistas elencados acima.

Muitos processos e patologias de ordem fisiológica podem, sem dúvida, ser a origem de determinados comportamentos, no entanto, a seguinte ressalva deve ser levada em conta: "a religião é cheia de objetos abstratos que provam

43 " [...] our reaction, involuntary and inarticulate and often half unconscious as it is, is the completest of all our answers to the question, "What is the character of this universe in which we dwell?" It expresses our individual sense of it in the most definite way."

44 "Why then not call these reactions our religion, no matter what specific character they may have?".

45 "It [religião] adds to life an enchantment which is not rationally or logically deducible from anything else. [...] Religious feeling is thus an absolute addition to the Subject's range of life. It gives him a new sphere of power." 
possuir um poder igual.”46 (Ibid., p. 47). Esses produtos da abstração também fazem parte de questões de ordem política, por exemplo. Muitas vezes somos impelidos a tomar ações ou apoiar certas figuras políticas não pela mera lógica que nos leva a um determinado resultado, mas por uma crença intuitivamente imbuída que, mais do que uma verdade atingida, nos aparece simplesmente como uma realidade a ser aceita. Como diz James, "A verdade é que na esfera metafísica e religiosa, razões articuladas são convincentes apenas quando nossos sentimentos inarticulados da realidade já decidiram a favor da mesma conclusão. [...] O instinto toma a dianteira, a razão apenas segue." ${ }^{47}$ (Ibid., p. 62). Abaixo, James nos lembra da formulação kantiana acerca da falta de conteúdo que certas crenças abstratas possuem e que, não obstante, ainda exercem influência na definição de nossas condutas.

Immanuel Kant defendeu uma curiosa doutrina sobre esses objetos de crença como Deus, o design da criação, a alma, sua liberdade, e a vida após a morte. Essas coisas, ele disse, não são de modo algum objetos de conhecimento propriamente dito. Nossas concepções sempre exigem um conteúdo sensorial para lidar, e como as palavras "alma", "Deus" e "imortalidade" não tratam de nenhum conteúdo sensorial distinto, segue-se que, teoricamente falando, elas são palavras desprovidas de qualquer significado. Entretanto, estranhamente, elas possuem um significado definitivo para nossa conduta. Nós podemos agir como se houvesse um Deus; sentir como se fôssemos livres; considerar a Natureza como se ela estivesse repleta de desígnios especiais; fazer planos como se fôssemos imortais; e então descobrimos que essas palavras de fato fazem uma diferença genuína em nossa vida mortal ${ }^{48}$. (JAMES, 2002, p. 47)

Nenhuma argumentação naturalista-científica é capaz de justificar ou de suspender certos pressupostos existenciais, pois não é por essa via que

46 "[...] religion is full of abstract objects which prove to have an equal power."

47 "The truth is that in the metaphysical and religious sphere, articulate reasons are cogent for us only when our inarticulate feelings of reality have already been impressed in favor of the same conclusion. [...] Instinct leads, intelligence does but follow."

48 "Immanuel Kant held a curious doctrine about such objects of belief as God, the design of creation, the soul, its freedom, and the life hereafter. These things, he said, are properly not objects of knowledge at all. Our conceptions always require a sense-content to work with, and as the words "soul," "God," "immortality," cover no distinctive sense-content whatever, it follows that theoretically speaking they are words devoid of any significance. Yet strangely enough they have a definite meaning for our practice. We can act as if there were a God; feel as if we were free; consider Nature as if she were full of special designs; lay plans as if we were to be immortal; and we find then that these words do make a genuine difference in our moral life." 
as pessoas chegam a tais posições em primeiro lugar. Os impulsos religiosos estão neste nebuloso e amplo terreno da intuição, qualquer definição ou inspeção de cunho analítico ou sistematizante é aceita ou descartada partindose dessa mesma ótica previamente incorporada. Portanto, a cosmovisão tácita que nos serve como norte existencial leva James a concluir que "Essa absoluta determinabilidade de nossa mente por abstrações é um dos fatos fundamentais de nossa constituição humana." ${ }^{49}$ (Ibid., p. 49).

Em suma, a religião, nos termos de James, pode ser definida como: a) uma cosmovisão de caráter utilitário da espécie humana; b) um conjunto de crenças predominantemente irrefletido e; c) abstrações articuladas que são fundantes no tocante à esfera das condutas éticas. Dito isso, vejamos a seguir a descrição que James oferece às duas posturas básicas que dividem os homens, a saber, Healthy-Mindedness e Sick Soul.

\section{II.}

Em Varieties of Religious Experience, William James assevera que "os homens tendem a considerar a felicidade ocasionada por uma crença religiosa como prova de sua verdade. Se um credo faz um homem feliz, ele quase que inevitavelmente o adota." ${ }^{50}$ (Ibid., p. 66). De fato, o que geralmente importa para o homem médio são os resultados práticos que desdobram de uma determinada crença. Se há um mínimo estável de felicidade ou contentamento, deve haver, no terreno ético, algum grau indiscutível de verdade no credo internalizado, mesmo na mais cética das hipóteses. Porém, nem sempre a ordem causal vai da crença à felicidade. Para um número considerável de pessoas, a felicidade ou satisfação existencial é como uma inclinação natural que, muitas vezes, está acima de circunstâncias econômicas ou bagagens religiosas: "Em muitas pessoas, a felicidade é congênita e inalienável. [...] Falo daqueles que quando a infelicidade é oferecida ou proposta, eles prontamente se recusam a senti-la, como se fosse algo ruim ou errado." ${ }^{51}$ (Ibid., p. 67). O que caracteriza esses indivíduos é, grosso modo, o fato de "não conseguirem

49 "This absolute determinability of our mind by abstractions is one of the cardinal facts in our human constitution."

50 " $[. .$.$] men come to regard the happiness which a religious belief affords as a proof of its$ truth. If a creed makes a man feel happy, he almost inevitably adopts it."

51 "In many persons, happiness is congenital and irreclaimable. [...] I mean those who, when unhappiness is offered or proposed to them, positively refuse to feel it, as if it were something mean and wrong." 
pensar mal do homem ou de Deus" ${ }^{52}$ (Ibid., p. 68). A existência de tais pessoas é permeada por uma contínua e tácita sensação de que tudo tem uma razão de ser ou de que tudo opera para um bem maior. Existe uma lógica na concatenação de eventos da realidade e não há razão de se colocar contra ela. O resultado da adoção desta perspectiva é o que James chama de healthymindedness, isto é, o estado psicológico padrão de pessoas possuidoras de um equilíbrio mental ou, simplesmente, de uma consciência saudável (em termos existenciais). Como dito, boa parte dessas pessoas atingem essa posição pela via congênita, por outro lado, outras conseguem o mesmo resultado a partir de uma atitude deliberada. De qualquer modo, ambas compõem o que James classifica como Consciência Saudável (Healthy-Mindedness).

Se, portanto, nomearmos de consciência saudável [healthy-mindedness] a tendência que observa a realidade e a percebe como boa, deve-se distinguir entre um modo mais involuntário e um mais voluntário ou sistemático de se ter um equilíbrio mental [being bealthy-minded]. Em sua ocorrência involuntária, a consciência saudável [bealthy-mindedness] é um meio de se sentir imediatamente feliz em relação às coisas. No caso sistemático, é um modo abstrato de conceber as coisas como boas ${ }^{53}$. (JAMES, 2002, p. 73)

Para figuras como Marie Bashkirtseff, diz James, a felicidade é algo espontâneo e quase que inevitável, como uma condição existencial préestabelecida. Outros, como Walt Whitman, também se enquadram na postura saudável em sua vivência, mas o caminho até ela passa por uma deliberação. Homens como Whitman possuem uma consciência saudável por colocarem uma conclusão prévia em prática. Há, nessa postura, uma ponderação e análise do real que leva pessoas como Whitman à resolução de que a existência possui uma carga metafísica moral que mantém o equilíbrio e a inteireza do cosmos. Seja de modo voluntário ou involuntário, o equilíbrio mental na categoria de healthy-mindedness faz com que as pessoas se sintam em plena harmonia com a realidade. Elas possuem um temperamento que carrega uma "incapacidade inata de sofrer prolongadamente" 54 (Ibid., p. 103). Elas

52 "[...] can think no ill of man or God".

53 "If, then, we give the name of healthy-mindedness to the tendency which looks on all things and sees that they are good, we find that we must distinguish between a more involuntary and a more voluntary or systematic way of being healthy-minded. In its involuntary variety, healthy-mindedness is a way of feeling happy about things immediately. In its systematical variety, it is an abstract way of conceiving things as good."

54 "[...] healthy-minded temperament, the temperament which has a constitutional incapacity for prolonged suffering". 
estão em sintonia com o próprio Ser, digamos assim. Mesmo os dolorosos e maléficos eventos da vida são percebidos como elementos que corroboram a visão de um todo coerente, balanceado e, em última instância, divinizado. Elas seguem à risca o preceito da primeira epístola aos Tessalonicenses que orienta, em 5:18, a dar graças a tudo que é, que foi e que será. A construção da visão desse grupo de pessoas está arraigada numa metafísica religiosa na qual prevalece uma ótica teleológica para interpretar as ocorrências do mundo. Algumas pessoas podem até mesmo não enxergar necessariamente uma causa supranatural para um determinado evento qualquer, mas percebêlo, acima de tudo, como positivo é característico da consciência saudável. Por esse prisma, a morte de alguém amado ou o fim de uma relação pode ser fonte de uma dor inimaginável, mas nunca será um fato que a médio e longo prazo trará desequilíbrio psíquico, muito menos a supressão da postura otimista em relação à vida. Do outro lado, há aqueles que adotam uma atitude diametralmente oposta sobre a existência. A alma enferma (sick soul) segue uma tendência de desequilíbrio que pode ser melhor compreendida no uso que James faz de outros dois conceitos.

Inspirado nos escritos de Francis W. Newman, James indica outro meio de caracterizar os de consciência saudável e os de alma enferma. Aqueles permeados por um otimismo existencial intrínseco são chamados de nascidos-uma-vez (once-born). Os de alma enferma, por outro lado, ao encontrar no mundo obstáculos que dificultam a visão de uma totalidade moral e coerente, são classificados como nascidos-de-novo (twice-born). O principal embargo na condição existencial das almas enfermas (mesmo que elas não consigam concebê-lo adequadamente) é o clássico problema do mal. Para uma alma enferma, o mal faz da realidade um lugar de forças cósmicas incompatíveis, diminuindo ou até mesmo extinguindo a possibilidade de uma ética verdadeiramente fundamentada. Se uma consciência saudável naturalmente minimiza o mal ou o percebe dentro de uma totalidade boa, a alma enferma, por sua vez, não consegue deixar de "maximizar o mal"55 (Ibid., p. 106). A ocorrência do mal alimenta o substrato que fundamenta o eventual domínio de afetos debilitantes como melancolia, depressão ou ressentimento. Somente uma purificação ou renovação moral por meio de eventos significativos como iniciação religiosa, terapia, sacramentos, uso controlado de substâncias farmacológicas ou algum rito pode marcar uma

55 "Now in contrast with such healthy-minded views as these, if we treat them as a way of deliberately minimizing evil, stands a radically opposite view, a way of maximizing evil". 
verdadeira expurgação espiritual capaz de iniciar a mudança necessária para o irrompimento de uma nova postura ética. A alma enferma, pois, é a disposição psicológica daqueles que precisam morrer para, enfim, viver. Deve ocorrer algum ponto de inflexão que demarque um antes e um depois em suas vidas para que seja possível a percepção do mundo com novos olhos, isto é, algo derradeiro deve acontecer para que um novo conjunto de crenças possa ser firmemente estabelecido ou, para usarmos a definição ampliada de James, a alma enferma é aquela que passa pela incorporação tardia de alguma religião; uma troca de pele, por assim dizer. Ela pode ou não ser institucionalizada, como também pode ser algum humanismo secular ou até mesmo a religião na qual um indivíduo foi criado e que nunca realmente se enraizou em sua existência ética diária. O que importa é que alguma espécie de evento precisa ocorrer para que uma postura ética possa, enfim, ser internalizada a partir de fundamentos realmente consolidados. A alma enferma, em poucas palavras, padece de uma cosmovisão marcada por uma incompletude axiomática. Essa situação é contornável, diz James, por diversas vias, ou seja, uma religião - agora no sentido institucional do termo - é apenas mais uma dessas variadas "maneiras de se atingir a unidade; e o processo de remediar a incompletude interior e reduzir a discórdia interna é um processo psicológico geral, que pode ocorrer com qualquer tipo de material mental, e não precisa necessariamente assumir a forma religiosa." ${ }^{56}$ (Ibid., p. 139). Mesmo que o indivíduo não adote a coleção de proposições de uma religião organizada específica, ele terá (se quiser sair desse limbo existencial) que internalizar pressupostos ético-existenciais que, apesar de não serem justificáveis em termos estritamente racionais, funcionam como condição sine qua non para uma postura não-patológica durante a vida. Dito de outro modo, "o renascimento pode ser o afastamento da religião [institucional] para a incredulidade" 57 (Ibid., p. 139), porém, esta incredulidade ou secularidade - que se torna então a cosmovisão - é, pela definição de James, uma espécie de religião, pois carrega pressupostos que, no fundo, servem como guias existenciais não-verificáveis cientificamente.

\footnotetext{
56 "But to find religion is only one out of many ways of reaching unity; and the process of remedying inner incompleteness and reducing inner discord is a general psychological process, which may take place with any sort of mental material, and need not necessarily assume the religious form."

57 " $[. .$.$] the new birth may be away from religion into incredulity".$
} 
A vantagem de uma consciência saudável é que ela concebe o bem e a justiça como características fundamentais do Ser. Desse modo, ela "exclui o mal de seu campo de visão" 58 (Ibid., p. 73). O mal é apreendido dentro do 'grande esquema das coisas' no qual uma moral suprema sempre prevalece. Tal postura, como James frisa, é inegavelmente útil no sentido de repelir afetos de desânimo ou cinismo. Um equilíbrio mental consegue ressignificar o mal, como quando Santo Agostinho, influenciado pelo neoplatonismo de Plotino, defendeu que o mal não deve ser concebido como substância, mas como simples ausência do bem. O mal não é um ser, mas a falta de ser. A única substância é Deus, logo, o mal é um não-ser ${ }^{59}$. Desse modo, para usarmos a terminologia de James, o maniqueísmo combatido por Agostinho pode ser pensado como uma espécie de teologia de almas enfermas que, para dar conta do mal, admitem sua existência como substância e oferecem como solução um gnosticismo que repudia a matéria como intrinsecamente má. Uma consciência saudável, no entanto, tende a apreender a totalidade da existência em um único princípio: "o contraste comum entre o bem e o mal parece ser englobado em uma esfera superior, uma excitação onipotente que envolve o mal” ${ }^{60}$ (Ibid., p. 75).

Para a consciência saudável, o que verdadeiramente importa é o "domínio de seus pensamentos" ${ }^{61}$ (Ibid., p. 74). Deixar se levar pela infelicidade não só é tido como algo doloroso, mas errado e, acima de tudo, inútil. Se o objetivo é chegar à felicidade ou ao contentamento, por que alimentar crenças que perpetuam uma instabilidade psíquica? A alma enferma, por sua vez, encontra (ou coloca, se preferir) mais resistência. Ela carrega um constante desencantamento da existência, mitigando assim sua vitalidade, o que leva James a também chamá-la de "mente mórbida" 62 (Ibid., p. 108) ou "consciência mórbida" 63 (Ibid., p. 130), dada sua postura existencial excessivamente pessimista e inclinada a captar a "experiência do mal como algo necessário." ${ }^{44}$ (Ibid., p. 129). Tal postura se desdobra em três

\footnotetext{
58 "Systematic healthy-mindedness, conceiving good as the essential and universal aspect of being, deliberately excludes evil from its field of vision".

59 Cf. AGOSTINHO. Confissões. (2011).

60 " [...] the ordinary contrast of good and ill seems to be swallowed up in a higher denomination, an omnipotent excitement which engulfs the evil".

61 "[...] it is the ruling of your thoughts which proves to be your principal concern".

62 "[...] morbid mind".

63 "[...] morbid-mindedness".

64 "Arrived at this point, we can see how great an antagonism may naturally arise between the healthy-minded way of viewing life and the way that takes all this experience of evil as something essential."
} 
tipos de almas enfermas, onde cada uma foca em um aspecto das diferentes manifestações do mal: "Uma delas nos mostra a fortuidade das coisas mortais; a outra, o sentido do pecado; e a última descreve o medo do universo." ${ }^{\prime 65}$ (Ibid., p. 129). James oferece exemplos para cada tipo, porém, vamos nos ocupar a seguir apenas do primeiro, personificado na figura de Liev Tolstói.

Pela leitura da obra Uma Confissão ${ }^{66}$ (1882), James demonstra como Tolstói - exemplo de alma enferma - se deixa abater pela melancolia e acaba por entrar em um estado de apatia perante a vida. Tolstói nos conta em seu escrito autobiográfico que, durante um considerável período de tempo, o sentido da vida obliterou-se e a coloração da existência padeceu. Toda apreensão tácita de sentido da realidade desvaneceu, dando lugar ao incessante e inquietante questionamento acerca da razão de continuar ou não a viver.

Por volta dos cinquenta anos de idade, Tolstói relata que começou a ter momentos de perplexidade, do que ele chama de impedimento, como se ele não soubesse "como viver", ou o que fazer. É óbvio que esses eram momentos em que a excitação e o interesse que nossas funções naturalmente possuem tinha cessado. A vida tinha sido encantadadora, e agora estava simplesmente sóbria, mais do que sóbria, morta. As coisas não tinham sentido para quem o sentido sempre tinha sido auto-evidente. As questões "Por quê?" e "O que vem depois?" começaram a perturbá-lo com mais e mais frequência ${ }^{67}$. (JAMES, 2002, p. 122).

Para a consciência saudável, o infortúnio acima não é nem um pouco familiar. A pior das conjunturas ainda faz parte de uma totalidade divina e, consequentemente, moralmente justificável e suportável. No estado de equilíbrio psíquico não entra em questão a validade da existência ou as razões para continuar ou desistir. Tolstói se percebeu nessa situação apenas em um período tardio de sua vida, porém, esse é um elemento constante para muitos outros indivíduos e que, geralmente, surge muito mais cedo. Há uma

65 "[...] One of them gives us the vanity of mortal things; another the sense of sin; and the remaining one describes the fear of the universe".

${ }_{66}$ Cf. TOLSTÓI, Liev. Uma Confissão (2017).

67 "At about the age of fifty, Tolstoy relates that he began to have moments of perplexity, of what he calls arrest, as if he knew not "how to live," or what to do. It is obvious that these were moments in which the excitement and interest which our functions naturally bring had ceased. Life had been enchanting, it was now flat sober, more than sober, dead. Things were meaningless whose meaning had always been self-evident. The questions "Why?" and "What next?" began to beset him more and more frequently." 
dificuldade para as almas enfermas de lidarem com certos acontecimentos e afetos, aproximando-as de uma perspectiva não-unitária do mundo que prepara o terreno para o descontentamento e a penúria espiritual. Isso impossibilita a atitude de um estável relacionamento harmônico com o Ser, embaraçando as mais cotidianas das atividades. Inevitavelmente, tal postura nos leva a dois caminhos possíveis: definhamento existencial ou renascimento ético-religioso. O renascimento, no entanto, não significa a pura instauração ou passagem para a condição de consciência saudável, pois, para James, é impossível eliminar o aspecto mórbido da ótica enferma. A única saída viável passa por uma purificação ou redenção [deliverance] na qual o mal é incluído dentro de uma perspectiva renovada onde se concede ao indivíduo a base que permite, enfim, o afastamento de afetos debilitantes. Portanto, a reintrodução de um sentido existencial, para a alma enferma, não significa a eliminação da "plena presença do mal" ${ }^{68}$ (Ibid., p. 148), mas sim um processo de expiação que oferece um florescimento ético que parte da própria perspectiva mórbida anterior, incorporando-a. Assimilar uma nova cosmovisão não faz da alma enferma uma consciência saudável, pois, mesmo quando o abatimento é superado, há um elemento perene de tristeza e pessimismo. Assim como Tolstói, John Bunyan também era uma alma enferma e, ao analisar ambos, William James conclui que "Nem Bunyan ou Tolstói poderiam se tornar o que chamamos de consciência saudável. Eles beberam demais do copo da amargura para esquecerem seu sabor [...] a tristeza foi preservada como um ingrediente menor no coração da fé que a superou" ${ }^{69}$ (Idem). Não há condições de uma alma enferma auferir o mesmo tipo de equilíbrio mental da consciência saudável. A felicidade atingível é aquela onde não há uma supressão do mal, mas sim a sua inclusão dentro de uma nova postura: "O processo é de redenção, e não mera reversão à saúde natural, e aquele que sofre, quando salvo, é salvo pelo que lhe parece um segundo nascimento" 70 (Ibid., p. 125).

\footnotetext{
68 "Tolstoy does well to talk of it as that by which men live; for that is exactly what it is, a stimulus, an excitement, a faith, a force that re-infuses the positive willingness to live, even in full presence of the evil perceptions that erewhile made life seem unbearable."

69 "But neither Bunyan nor Tolstoy could become what we have called healthy-minded. They had drunk too deeply of the cup of bitterness ever to forget its taste, and their redemption is into a universe two stories deep. Each of them realized a good which broke the effective edge of his sadness; yet the sadness was preserved as a minor ingredient in the heart of the faith by which it was overcome."

70 "The process is one of redemption, not of mere reversion to natural health, and the sufferer, when saved, is saved by what seems to him a second birth".
} 
A necessidade de um renascimento para as almas enfermas leva James à questão sobre "tipos diferentes de religião para tipos diferentes de necessidade" 71 (Ibid., p. 109). Já que uma consciência saudável "não precisa de salvação [deliverance] de nenhum fardo antecedente" 72 (Ibid., p. 68), o requisito essencial para os nascidos-de-novo diz respeito ao caráter de expiação ou purgação que determinada cosmovisão pode oferecer. Para pessoas como Tolstói e Bunyan, "a redenção [deliverance] deve ser tão forte quanto o descontentamento"73 (Ibid., p. 129). Por conta disso, James argumenta, o cristianismo e o budismo seriam as religiões mais desenvolvidas da humanidade, pois além delas possuírem características que satisfazem as consciências saudáveis, elas trazem elementos de pessimismo e de remissão que servem às almas enfermas.

As religiões mais completas seriam, portanto, aquelas em que os elementos pessimistas são melhor desenvolvidos. Budismo, é claro, e Cristianismo são as melhores das conhecidas por nós. Elas são essencialmente religiões de redenção: o homem deve morrer para uma vida irreal antes que ele possa nascer para a vida real ${ }^{74}$. (JAMES, 2002, p. 131).

A primeira das Quatro Nobres Verdades ('tudo é sofrimento') e a descrição da contingência e da injustiça terrena, brilhantemente ilustradas nos livros de Jó e Eclesiastes, lidam com o fator pessimista. O estado de nirvana e a remissão cristã dos pecados tratam do aspecto redentor que promete a quebra do ciclo de sofrimento. James não explica o porquê da escatologia judaica não ser o suficiente para colocar o judaísmo ao lado do budismo e do cristianismo. Nos arriscamos a afirmar que o caráter étnico dos judeus seja o caso, já que não há no Antigo Testamento nada análogo à instrução universalista da Grande Comissão presente, especialmente, no final do evangelho de Mateus ${ }^{75}$ e expandida nas epístolas de Paulo $^{76}$. Com ela, o cristianismo permite que qualquer indivíduo se entregue ao credo, iniciando um novo tipo

\footnotetext{
71 "[...] different types of religion to different types of need".

72 "[...] needs no deliverance from any antecedent burden."

73 "But the deliverance must come in as strong a form as the complaint".

74 "The completest religions would therefore seem to be those in which the pessimistic elements are best developed. Buddhism, of course, and Christianity are the best known to us of these. They are essentially religions of deliverance: the man must die to an unreal life before he can be born into the real life."

75 Cf. FEUERBACH, Ludwig. A Essência do Cristianismo (2013).

76 Cf. BADIOU, Alain. Saint Paul: la foundation de l'universalisme (1997).
} 
de vivência que independe de sua hereditariedade. De qualquer modo, tais religiões, segundo James, oferecem tanto a unidade cosmológica de conforto moral (familiar às consciências saudáveis), como a ótica mórbida necessária às almas enfermas para a instauração de uma postura ética renovada que consiga englobar os diversos elementos da existência. Assim, cristianismo e budismo, segundo James, seriam os mais completos sistemas religiosos do homem.

\section{Conclusão}

William James demonstra que o tipo de saber que há em religiões ocidentais e orientais não deve ser encarado como um mero apanhado de mitologias arcaicas de um longínquo período pré-científico, tampouco como um desdobramento patológico de sexualidades desviadas ou desequilíbrios no córtex e qualquer parte do sistema nervoso. $\mathrm{Na}$ verdade, as religiões institucionalizadas cristalizaram cosmovisões que, mesmo com a ausência de deuses criadores do universo (como nos casos budista e xintoísta), fundamentam diferentes perspectivas éticas e existenciais sobre a vida. Por conta da adoção da perspectiva do pragmatismo filosófico, James não se preocupa com questões de ordem teológica para examinar o que é uma religião. Até mesmo sistemas humanistas seculares se enquadram no sentido ampliado oferecido por James. Sua investigação trata de averiguar as consequências comportamentais da internalização de uma determinada cosmovisão, isto é, de um conjunto de pressupostos que são assimilados não de modo analítico, mas intuitivo. Tais pressupostos existenciais tácitos fundamentam a ação dos homens e é pela análise de seus frutos, e não de suas raízes, que podemos julgá-los. Desse modo, a conclusão de James é, inevitavelmente, a de oferecer um parecer positivo sobre as religiões (institucionalizadas ou não), pois é indiscutível o papel que elas exercem no equilíbrio psíquico dos homens. Por fim, ao levarmos em conta a distinção entre consciência saudável (Healthy-Mindedness) e alma enferma (Sick Soul) proposta em Varieties of Religious Experience, chega-se à conclusão de que o cristianismo e o budismo são as religiões mais desenvolvidas por oferecerem uma forma superior de lidar com o problema do mal e a questão da redenção.

\section{Referências}

AGOSTINHO. A Cidade de Deus. Lisboa: Fundação Calouste Gulbenkian, 1996;

Confissões. Petrópolis, RJ: Editora Vozes, 2011; 
AQUINO, Tomás de. Suma Teológica, Vol. I. São Paulo, SP: Edições Loyola, 2001;

BADIOU, Alain. Saint Paul: la foundation de l'universalisme. Paris: Presses Universitaires de France, 1997;

BRANDOM, Robert B. Perspectives on Pragmatism: Classical, Recent and Contemporary. Cambridge: Harvard University Press, 2011.

FEUERBACH, Ludwig. A Essência do Cristianismo. Petrópolis, RJ: Editora Vozes, 2013; Preleções Sobre a Essência da Religião. Petrópolis, RJ: Editora Vozes, 2009;

FREUD, Sigmund. O Futuro de uma Ilusão. Porto Alegre, RS: Editora L\&PM, 2010; Totem e Tabu e Outros Textos. São Paulo, SP: Companhia das Letras, 2012;

HUME, David. História Natural da Religião. São Paulo, SP: Editora Unesp, 2004;

JAMES, Williams. Pragmatism and Other Writings. London: Penguin Books, 2000;

. Varieties of Religious Experience: A Study in Human Nature. London \& New York: Routledge, 2002;

. The Will to Believe, Human Immortality and Other Essays in Popular Philosophy. New York, NY: Dover Publications, 1960;

MATTOS, Rafael da Silva. Pragmatismo Americano: O Direito de Crer diante da Morte de Deus. Horizonte, V. 8, n. 18, pp. 104-126, jul./set. 2010;

MORESCHINI, Claudio. História da Filosofia Patrística. São Paulo, SP: Edições Loyola, 2008; PUTNAM, Hilary. A Permanência de William James. Tradução de Clayton Foschiani. Cognitio: Revista de Filosofia. Volume 7, Número 2, pp. 210-220, 2010.

PUTNAM, Hilary; PUTNAM, Ruth Anna. Pragmatism as a Way of Life: The Lasting Legacy of William James and John Dewey. Cambridge: Harvard University Press, 2017;

RUSSELL, Bertrand. História da Filosofia Ocidental - Livro 2: A Filosofia Católica. Rio de Janeiro, RJ: Editora Nova Fronteira, 2015;

SCOTT, David. William James and Buddhism: American Pragmatism and the Orient. Religion. Volume 30, Número 4, pp. 333-352.

TOLSTÓI, Liev. . São Paulo, SP: Editora Mundo Cristão, 2017.

Submetido em: 6-6-2020

Aceito em: 16-9-2020 